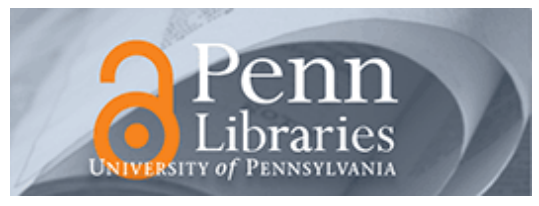

University of Pennsylvania

ScholarlyCommons

Management Papers

Wharton Faculty Research

$11-2015$

\title{
Shifts and Ladders: Comparing the Role of Internal and External Mobility in Managerial Careers
}

\author{
Matthew J. Bidwell \\ University of Pennsylvania \\ Ethan Mollick \\ University of Pennsylvania
}

Follow this and additional works at: https://repository.upenn.edu/mgmt_papers

Part of the Management Sciences and Quantitative Methods Commons

\section{Recommended Citation}

Bidwell, M. J., \& Mollick, E. (2015). Shifts and Ladders: Comparing the Role of Internal and External Mobility in Managerial Careers. Organization Science, 26 (6), 1629-1645. http://dx.doi.org/10.1287/ orsc.2015.1003

This paper is posted at ScholarlyCommons. https://repository.upenn.edu/mgmt_papers/196

For more information, please contact repository@pobox.upenn.edu. 


\title{
Shifts and Ladders: Comparing the Role of Internal and External Mobility in Managerial Careers
}

\begin{abstract}
Employees can build their careers either by moving into a new job within their current organization or else by moving to a different organization. We use matching perspectives on job mobility to develop predictions about the different roles that those internal and external moves will play within careers. Using data on the careers of master of business administration alumni, we show how internal and external mobility are associated with very different rewards: upward progression into a job with greater responsibilities is much more likely to happen through internal mobility than external mobility; yet despite this difference, external moves offer similar increases in pay to internal, as employers seek to attract external hires. Consistent with our arguments, we also show that the pay increases associated with external moves are lower when the moves take place for reasons other than career advancement, such as following a layoff or when moving into a different kind of work. Despite growing interest in boundaryless careers, our findings indicate that internal and external mobility play very different roles in executives' careers, with upward mobility still happening overwhelmingly within organizations.
\end{abstract}

\section{Keywords}

worker mobility, careers, hiring, promotion, labor markets

\section{Disciplines}

Management Sciences and Quantitative Methods 


\title{
SHIFTS AND LADDERS: COMPARING THE ROLE OF INTERNAL AND EXTERNAL MOBILITY IN EXECUTIVE CAREERS
}

Matthew Bidwell

Ethan Mollick

November 2014

\begin{abstract}
Workers can build their careers either by moving into a different job within their current organization or else by moving into a new job within a different organization. We use matching perspectives on job mobility to develop predictions about the different roles that those internal and external moves will play within their careers. We propose that internal and external mobility are associated with very different rewards: upwards progression into a job with greater responsibilities is much more likely to happen through internal mobility, but external moves will nonetheless offer similar increases in pay, as employers seek to attract external hires. We also examine how these predictions change when moves take workers across job functions as well as when external mobility happens involuntarily. Analyses of data on the careers on MBA alumni are used to support these arguments. Despite growing interest in boundaryless careers, our findings indicate that internal and external mobility play very different roles in executives' careers, with upwards mobility still happening overwhelmingly within organizations.
\end{abstract}


Individual careers, the paths that take people from job to job over time, are critical to our experience of work. Each job differs in the rewards that it provides in terms of money, status, and responsibility, as well as its fit with our own goals and preferences. Often, it is through the progression of our careers that we are able to move into jobs that offer greater rewards and a better fit with what we want (e.g. Jovanovic 1979; Sorensen 1977). Early research on careers typically explored how workers accrued rewards as they advanced within organizations (e.g. Gunz 1989; Stewman and Konda 1983; White 1970), but modern careers increasingly also encompass moves across organizations (Arthur and Rousseau 1996; Bidwell and Briscoe 2010), raising new questions about how different kinds of job moves advance careers.

In particular, the increasing prevalence of cross-firm mobility raises the question of whether these "external" moves play similar roles in advancing careers to the "internal" moves that take place within organizations, or whether they instead provide different kinds of career gains. Answering this question can help us to understand whether the increasing boundarylessness of careers is creating broader changes in the kinds of rewards that workers receive through their job moves. Inkson et al. (2012) argue that even as careers increasingly cross boundaries, they are likely still enabled and constrained by those boundaries. Comparing internal and external moves also allows us to develop this perspective by establishing how firm boundaries shape careers. Comparing internal and external mobility can also help us to understand when it is more important to study each of them: if certain career gains are mainly achieved through internal mobility, then scholars interested in those gains need to focus on the opportunities for internal mobility; the same is true for external mobility.

Comparing the career gains experienced in internal versus external mobility is also important for workers seeking to plan their careers. They need to understand both the kinds of advancement that they can expect to achieve by external moves, and the career goals best served by finding jobs with good prospects for internal mobility. Knowledge of how internal and external moves fit into careers is also critical to employers, who need to understand how their incentives and hiring strategies might fit with workers' goals and career paths. 
Current research offers only an incomplete account of the comparison between these internal and external moves, though. Some studies have examined how the cumulative numbers of internal and external moves affect workers' ultimate pay or job satisfaction (le Grand and Tahlin 2002; Valcour and Tolbert 2003), generally finding greater pay gains for internal moves than external. Although these studies provide important evidence on the long-run impact of job moves, they do not explore how each individual move contributes to workers' career growth; nor, given their focus on pay, do they explore how internal and external moves affect such basic features of jobs as the kind of work being done or the level of responsibilities. Other studies have compared the pay, performance, and experience of workers being hired versus promoted into jobs within specific firms (Baker et al. 1994; Bidwell 2011; Chan 2006), but lacking data on the jobs that external hires are moving from, they did not address how the changes in pay and responsibilities experienced by hires compared to internal movers. We believe that this is the first study to make such a comparison, developing theory on how firm boundaries affect careers and empirically testing how workers who move internally versus externally experience different changes in three central outcomes: the responsibilities they hold, the pay that they receive, and the job functions that they work in.

We apply models of labor market matching from sociology and economics (e.g. Heckman and Sedlacek 1985; Logan 1996) to develop theory about how firm boundaries affect careers, making new predictions about the different effects of internal and external mobility. Our arguments suggest that internal mobility tends to take workers into jobs with greater responsibilities and status, as employers' knowledge of their own employees reassures them that they will be able to do the job. Because external moves are less likely to take workers into higher level jobs, we argue that workers can only be persuaded to move if they receive substantial increases in pay or a substantial changes in the nature of their work, or are forced to move by the disappearance of their old job. In this way, we propose that mobility has very different effects on responsibilities compared to pay, depending on whether it takes place within or across firms and within or across functional boundaries. 
We test these arguments using data from a survey of alumni from an MBA program. Our unique data provide insight into how these career dynamics play out within a population of executives with highly valued human capital, for whom careers of vertical achievement are the norm. Most careers in our sample contained a combination of internal and external moves, but those moves played very different roles in our respondents' careers. Climbing up the job ladder into jobs with greater responsibilities overwhelmingly took place within organizations. Moving across firms, by contrast, allowed workers to shift to a different ladder, but at the same rung that they were on before, albeit with more pay. Consistent with such a pattern, we also found that respondents' pay at the time of the survey was associated with the number of internal moves (but not external moves) that they had made. Despite the increasing prevalence of inter-organizational mobility (Hollister 2011) and a declining willingness of employers to support career progression within firms (Cappelli 1999), these findings suggest that organizations continue to play a vital role in allowing the kinds of workers that we studied to move into higher level jobs over time.

\section{THEORY}

Jobs, the basic units of our theory, represent bundles of tasks that both the organization and workers recognize as falling within the responsibilities of a particular worker (Cohen 2013). Job mobility is then defined as a substantial, semi-permanent (as opposed to project-based) change in the job that a worker is doing. A change in job can therefore involve a wholesale change in the nature of the tasks that a worker performs (as might happen when a worker moves functions); a substantial change in the level of status and responsibilities associated with the job (as happens on promotion); a change in the organizational context in which the work is carried out (as happens when a worker moves departments or organizations); or some combination of these. In each case, both the worker and the organization would recognize such changes as a move across jobs. Many studies demonstrate that moving jobs in this way allows workers to increase their wages much more rapidly than they could if they remained within their jobs (Baker et al. 1994; McCue 1996; Topel and Ward 1992), making such mobility a particularly important topic of study. 
We develop our theory using a matching approach to understanding job mobility (Heckman and Sedlacek 1985; Logan 1996) which emphasizes that two conditions must be met for any move across jobs to take place. First, matching models emphasize that mobility can only take place when an employer is prepared to employ the worker in the new position (Logan 1996). The worker therefore needs to be able to persuade the employer that they have the skills necessary to do the job, either based on their demonstrated achievements, or else using their reputation, social networks and/or political capital.

The second condition for mobility is that the worker must be prepared to accept the new job. In some cases, they may move because their prior job has ceased to exist, as happens with involuntary turnover. More commonly, though, workers move because they believe that the new job will be an improvement on their current position. There is substantial heterogeneity in the reasons why workers might prefer another job to their current one, reasons that can include a desire for career advancement, a dislike of the current manager or organizational setting, a wish to pursue different kinds of work, geographical relocations, and so on. Many of these reasons may underlie moves both across firms and within firms, but we do not assume that workers always undertake internal and external moves for the same reasons. Indeed, we expect that the reasons that workers move internally versus externally reflect (and thereby reinforce) the differences in the kinds of gains that they can achieve through those moves. It is understanding the differences in those gains achieved through internal and external mobility, given that the workers move, that is the main focus of our paper: how do internal and external moves affect responsibilities differently? What are their implications for pay? For the kinds of work being done? We explore the second question of when workers might enter into internal versus external mobility empirically but do not develop hypotheses about it.

Our theory development focuses on two kinds of career gains that workers might receive from internal and external moves. First, workers might look to achieve career progression through "vertical" increases in responsibilities and rewards (e.g. O'Mahony and Bechky 2006; Rosenbaum 1979). Many studies have demonstrated the important role that mobility into higher level jobs plays in driving both 
short term and long term pay growth (Baker et al. 1994; McCue 1996; Topel and Ward 1992). Second, workers also seek to increase the "horizontal" fit between the kinds of work they do and their own preferences and abilities. Such a search for fit plays a prominent role in economic theories of turnover (Jovanovic 1979) and is also consistent with psychological perspectives that emphasize dissatisfaction with the current job as a central driver of mobility (e.g. Griffeth et al. 2000; Lee and Mitchell 1994).

One way workers can achieve the twin goals of vertical mobility and horizontal fit is through moving jobs within organizations, either taking a promotion or moving laterally into a different position.

Alternatively, they can also pursue these goals by external mobility, moving firms to get increased pay or responsibility, or because they think a new job would fit them better. We propose, though, that some of these goals might be more easily achieved via internal mobility than external mobility, and vice versa, so that internal moves tend to provide different rewards compared to external moves. We also suggest that those differences between internal and external mobility may vary with the reasons that workers have for moving, such that firm boundaries have different effects when mobility primarily reflects a search for improved horizontal fit rather than vertical achievement.

Figure 1 outlines our main argument. We argue that the employers' side of the matching process looks very different when considering internal and external mobility, as employers use different information to assess whether a worker will fit a given job. We then explain how these changes in the employers' side of the matching process have knock-on effects on the kinds of rewards that jobs must offer workers, leading to differences in what workers can achieve through internal versus external mobility. We also develop our logic to explain how the pursuit of vertical gains and horizontal fit interact with one another, so that the kinds of vertical rewards that workers achieve in moving internally and externally depend on whether those moves also take workers across different functions.

[Insert Figure 1 About Here]

\section{Mobility and Vertical Rewards}

\section{Information Asymmetries and Effects on Responsibilities.}


Information asymmetries are a fundamental driver in our theory of the differences between internal and external mobility. A number of scholars have noted that employers have much more information about their own employees than they do about external candidates (e.g.Doeringer and Piore 1971; Gibbons and Katz 1991), and information asymmetries feature heavily in transaction cost approaches to employment (Bidwell and Keller 2014; Williamson et al. 1975). Because they can observe how their employees performed in prior roles, employers have an advantage in evaluating those workers' ability. Those advantages will shape how employers evaluate internal and external candidates for jobs.

Specifically, we propose that these information asymmetries will make it more difficult for workers to increase their responsibilities when moving across firms rather than within them. Any worker seeking to advance into a job with more responsibility faces the challenge of persuading an employer that they have the requisite skills for the job (O'Mahony and Bechky 2006). Within the firm, workers can demonstrate through their day-to-day performance that they are capable of taking on more responsibilities. External employers, though, lack access to such performance information and will instead demand easily observed credentials to qualify the worker for the job. Bidwell (2011) draws on this argument to suggest that workers hired into jobs should have stronger formal credentials, such as education and experience, than those being promoted from inside. His argument also has undeveloped implications for workers' careers.

In particular, a critical credential that employers consider in assessing potential recruits is the track record of jobs that they have held (Bills 1990). A prospective employer that wants to know whether a worker has the skills necessary for a specific job can look at whether that worker has previously held a similar job at a similar level. Having held such a job indicates that the worker had previously demonstrated the capacity to be selected for such responsibilities. That prior experience is even more valuable if the worker is able to demonstrate a track record of achievement in that job, or even just an ability to avoid dismissal from the position. Hence, the less information that an employer has on a candidate's skills and abilities, the more they will emphasize prior experience with a similar level of 
responsibilities to the job that they are filling.

The central implication of this argument is that many workers will have opportunities to move into jobs with more responsibilities within their current firms; if those workers are performing well, they can expect their employer to move them into a job with greater responsibilities. By contrast, all workers will find it very difficult to persuade external employers to hire them into a job with increased responsibilities: those external employers don't know whether the worker is currently performing well or not. Instead, those external employers will focus on hiring people who have already held a similar level of responsibility. From the perspective of the worker, this means that moves into jobs with greater responsibility are more likely to occur through internal mobility than external moves. We predict that: H1: Internal job moves are associated with greater increases in responsibilities than external job moves (both voluntary and involuntary).

\section{Compensation: Paying People to Move}

If internal mobility is associated with greater increases in responsibilities than external mobility, then it should also be associated with greater increases in pay. Substantial amounts of theoretical and empirical work show that pay usually increases with responsibility. Doeringer and Piore (1971), for example, argue that firms need to offer higher pay for higher-level jobs in order both to motivate workers to climb the career ladder and to maintain the status of workers with more responsibility. The signal of ability that promotion provides and the more valuable work that promoted workers perform also encourages firms to match increases in responsibility with increases in pay (Waldman 1984). Empirical studies demonstrate a strong relationship between promotions in responsibility and increases in pay (e.g. McCue 1996), with Baker et al (1994) finding that $70 \%$ of variation in wages within a large corporation can be explained by

workers' job levels. If external moves lead to lower increases in responsibility than internal moves, a clear corollary is that those moves should also lead to lower increases in pay:

H2a: Internal job moves are associated with greater increases in pay than are external moves (both voluntary and involuntary) 
A detailed application of our matching logic suggests that these differences in how internal and external moves are compensated may be limited, however. If, as we proposed in H1, external employers are reluctant to hire workers for jobs at higher levels of responsibility, then career progression in external moves should be limited. Yet our matching approach emphasizes that mobility will only occur when workers also see a benefit to moving. If external employers offer workers jobs that are similar to the ones that they already hold, why would the workers accept them? One possibility is that external mobility could be very rare, as few workers are prepared to move and firms are suspicious of those that are (Greenwald (1986) formalizes this argument). Yet the literature is full of studies that document extensive mobility between similar jobs within the same industry (e.g. Campbell et al. 2012; Dokko and Rosenkopf 2010; Groysberg 2010; Mollick 2012). Although firms might prefer to fill jobs internally, they often lack a suitable internal candidate. As a consequence employers frequently look to hire from outside.

External employers therefore face the challenge of persuading workers to move jobs despite being unwilling to offer them more responsibilities than they already hold. We propose that one way that employers will do so is by offering increased pay. Although such a strategy increases the amount that the firm needs to pay to get the job done, those costs are often lower than the alternatives: either leaving the job unfilled; or hiring a worker who has not demonstrated a track record at that level, and who could perform very poorly and even damage the organization.

By way of illustration, consider an investment banker specializing in leading deals in the technology industry. If she is performing adequately, she could expect an eventual raise and promotion from her existing firm. Another bank, looking to expand its technology practice, might want to hire the banker to do her existing job, as she has a proven track record and a known reputation. The firm would be reluctant to hire her at a higher level, however, because they know little of her potential or her personality: she might have the skills to lead a small team, for example, but lack the ability to manage an entire department. In order to incentivize her to move firms without an increase in responsibility, the firm must be prepared to offer her a substantial raise over her current salary instead. 
These arguments have important implications for our central focus in this paper: understanding how the rewards associated with external moves differ from internal. Specifically, while external moves may involve much smaller increases in responsibility than internal moves, they may be associated with comparable increases in pay nonetheless. We predict:

H2b: Compared to internal moves, external voluntary moves increase pay more than they increase responsibility.

We argue that employers induce workers to move firms by increasing their pay. Yet some workers may have little choice but to move firms, having been forced to leave their prior organization, either because of downsizing or because of poor performance. Prior research has associated such involuntary turnover with substantial declines in pay (Gibbons and Katz 1991; von Wachter and Bender 2006). Our arguments highlight one reason why involuntary turnover may be associated with lower pay increases: where those workers need less inducement to move into a new job, employers will not need to offer them pay increases to take the job. Hence, we should not see the same decoupling between rewards and responsibilities for involuntary external moves that we see for voluntary moves:

H2c: The pay difference between external and internal moves will be greater when external moves are involuntary.

\section{Mobility and Horizontal Fit: And Now for Something Completely Different}

A further way in which internal and external moves may differ is in their ability to improve workers' horizontal fit with the work that they are doing. We focus in particular on how mobility allows workers to change their job function, which, similar to occupation (e.g. Tolbert 1996; Weeden 2002), defines the kinds of tasks that workers carry out day to day, and hence the skills that they use and the intrinsic rewards that they receive from their work. Functional changes therefore represent the most substantial way in which workers can change their horizontal fit with their job.

Workers may find opportunities to improve horizontal fit both within and across organizations. Within the organization, moves into a different function are likely to be helped by the employers' 
observation of their prior performance, which can help to persuade the employer that the worker could perform well in a different function. At the same time, though, a worker's ability to improve their horizontal fit by internal moves is constrained by the breadth of opportunities available within the worker's firm. One thing that defines organizations is their pursuit of a specific set of goals (Scott 2003), and performance of a defined set of activities. Although most organizations will contain the same basic functions, such as sales, marketing or accounting, other, more specialized, functions such as research, banking, consulting, teaching, or editing are found in only a small subset of organizations. Moving into or out of those specialized functions usually therefore requires moving into a different organization, carrying out very different kinds of work, usually in a different industry. ${ }^{1}$

As illustration, consider again the technology-focused investment banker from the previous example. She might decide that she is more interested in a consumer marketing role, rather than banking. This would require her to switch industries, as investment banks do not have many options for consumer marketing. Although she would not have functional experience in marketing, she may be able to find employers in other industries, such as the technology industry she covered, that find her skills in analysis and research useful in projecting future sales or analyzing competition. Certainly, she is likely to face substantial challenges in persuading external employers to hire her into such a different function. Such a move, though, would simply be impossible within her current firm, and even within her current industry. The way that different kinds of organizations contain very different kinds of jobs therefore makes external moves an important way by which workers can move into different kinds of job functions:

H3: External job moves (voluntary and involuntary) that span industry sectors are more likely to involve a change in function than are internal job moves.

\footnotetext{
${ }^{1}$ A similar effect of opportunities can also affect vertical mobility, particularly within small organizations where no higher level vacancies exist within a firm, workers must move firms to achieve further career growth. Our arguments suggest, though, that such moves are very hard to accomplish. Moreover, while a worker may face a limited number of higher level positions that they can be promoted into within a given firm, if they seek a very different kind of work they can find that there are no suitable positions at all.
} 


\section{Vertical Attainment versus Horizontal Fit: Managing the Tradeoffs}

In addition to being an important consequence of moving jobs, workers' search for horizontal fit also affects the vertical rewards that they can expect from internal and external mobility. Our matching model emphasizes that mobility requires workers to perceive a benefit from moving jobs. Vertical achievement and horizontal fit represent alternative benefits from mobility: where one is present, the other need not be. Applying such a logic allows us to add further nuance to our understanding of the differences between internal and external moves.

We have argued above that internal and external mobility have different effects on vertical achievement, with internal mobility leading to increases in responsibility and pay, while external mobility leads to increases in pay alone. Those differences imply that changes in function also have differential effects on vertical achievement for internal and external moves.

We turn first to the effects of changing function on internal moves. We have proposed that internal moves are more likely to increase responsibilities. Yet, those increases should be smaller where internal moves involve a shift in function. Where moves involve a substantial change in the work done, employers may be less confident in the workers' ability to handle higher level responsibilities. The worker will not have done such work before. In addition, moves across functions often involve moving to a different part of the organization, and information flows about employees are poor in many organizations, further reducing the advantages of internal moves over external. Furthermore, workers who are increasing their horizontal fit with the work will be comfortable moving even in the absence of increased responsibilities.

These arguments suggest that the increases in responsibilities received in internal moves are less when those moves involve changes in function. Such arguments also have clear implications for the difference between internal and external moves. We have argued that external moves tend not to involve increases in responsibility. Where moves cross functions, the differences between internal and external moves should therefore be muted. We propose that: 
H4a: The differences between the changes in responsibilities achieved through internal versus external moves (voluntary and involuntary) are smaller when moves involve a change in function.

Now consider the effects of changing function on external moves. We argued that external moves offer workers increases in pay in order to induce them to move jobs. When workers are changing function, however, the prospect of increased horizontal fit should play a major role in inducing a move; the lure of increased pay is no longer as necessary. To return to our example of the investment banker seeking to move into marketing, if she is interesting in changing function then she will likely be prepared to move without a pay raise. Pay raises should therefore be lower when external moves also involve a move across functions.

These implications help us to create more detailed predictions about the differences between internal and external moves. $\mathrm{H} 2 \mathrm{~b}$ argued that the need to induce external moves leads to a decoupling between pay and responsibilities: compared to internal moves, external moves involved a more substantial increase in pay than in responsibilities. Where pay is not used to induce moves across function, then we should not see this decoupling. As a consequence:

H4b: Pay increases for external voluntary moves are lower relative to internal moves when moves also involve a change in function.

\section{METHODS}

We studied internal and external mobility using a survey of MBA alumni from a leading US business school. Methodologically, this approach allowed us to gather longitudinal data on the careers of a largely homogeneous sample of workers entering reasonably similar jobs during their prime working years. The sample is not representative of the US workforce, being much better educated and rewarded than the mean worker, and predominantly taking jobs in a narrow set of occupations based around finance, consulting and general management. The sample, therefore, gives us particular insight into the careers of workers with very high human capital, who are well-placed to take advantage of the opportunities presented by inter-firm mobility (Marler et al. 2002). It also documents careers in occupations where 
workers are expected to progress into jobs of increasing levels of responsibility, making careers of vertical achievement the norm. More generally, this sample provides insight into the paths that workers take into some of the very highest paid jobs in society. MBA alumni surveys have therefore been used in several other studies of careers (e.g. Dobrev 2012; Dreher and Cox 2000).

\section{The Survey}

We conducted the survey using a web-based platform during the summer of 2011. Respondents were contacted by mail in advance to alert them to the survey and received repeated reminders by email. Those without recorded email addresses received paper copies of the survey. As an inducement to participate, respondents were offered a salary report that compared pay in different industries and cohorts. We also made telephone calls to a randomly selected subsample of 200 alumni who graduated in each of the years between 1990 and 2005 in order to encourage them to participate (we control for year in all analyses).

Because the survey response rate was lower for alumni who had graduated longer ago, we restrict the sample for our analyses to those who graduated since 1990, ensuring that we track a sample with comparable and adequate response rates. Specifically, we received responses with some usable information from $32 \%$ of the alumni whom we could contact that graduated on or after 1990, and responses that covered the full career from $23 \%$. This response rate is within the normal range for surveys of workers in demanding roles (Bertrand et al. 2009; Cycyota and Harrison 2006), and studies show that response rates are a very poor predictor of non-response bias (Groves and Peytcheva 2008). We assessed non-response bias by comparing the LinkedIn profiles of respondents and non-respondents from a subsample of 3,000 alumni. As noted, response rates fell with time since graduation, and we control for graduation year in all of our analyses. We found no significant differences in the response rate of individuals by industry or by gender. Among the most common titles, we found that response rate was significantly higher than the mean sample response rate among those with the title of Manager (8\% higher) or Principal (15\% higher), but not for other common titles, including both the senior titles of President, C-level titles, Directors, and the more junior titles of Associate or Vice President. These 
figures give us some confidence that our respondents were broadly representative of the sample. We do not restrict our analyses to respondents with full career information. Instead, our analyses use all responses with sufficient data to estimate the effects of individual moves. Robustness checks provided similar results when we restricted the data to those respondents who provided full career histories.

We asked the respondents to provide details of each job that they had held within each employer that they had worked for after graduating from the MBA. We told respondents: "You should consider a job as having changed if you had a significant promotion to a new title or rank in the organization that involved significant changes to your job tasks, number of people managed, or compensation. A job change is also a substantial change in the nature of the work that you performed, usually accompanied by a change in title or a move to a different organizational unit." This rubric fits our theoretical definition that moving jobs involves a change in level of responsibility, function or organizational context. It also emphasizes the mutual, formal recognition of a change in responsibilities that occurs on moving jobs, through changes in title and rank. Dropping job moves with incomplete data, those into or out of spells of unemployment that lasted for more than 6 months and those into or out of entrepreneurship, we end up with information on 5,548 moves across jobs made by 2,113 different respondents.

\section{Defining Mobility}

Our key independent variables relate to how workers moved jobs. We separated out involuntary external moves based on a question which asked respondents why they left each employer. They were given thirteen possible options, and allowed to select more than one. The $25 \%$ of external moves for which respondents answered that they moved because of "position eliminated," "company, office, workplace or plant closed," "discharged or fired," or "left by mutual agreement" were coded as external involuntary moves. All other moves between different organizations were coded as external voluntary moves, including the $8 \%$ of moves where the reason for the move was missing. Our results were similar when those moves were excluded from the analysis. It is important to acknowledge that some workers 
may have classified moves as voluntary even when they moved in advance of expected dismissals. Such effects should narrow the observed differences between voluntary and involuntary external mobility. ${ }^{2}$

\section{Job Characteristics.}

Change in log subordinates. Our main measure of responsibility is the total number of subordinates that worked in units managed by the respondent in each job. Although some technical specialists can progress through their careers without managing anyone, we believe that size of units managed provides the most general measure of responsibilities for executives across a wide variety of industries: the more individuals that a worker manages in any field, the greater the span of activities that they can affect. Such "leverage" ratios are important both in general management jobs, and in the professional services fields such as consulting and investment banking that are popular among MBAs. As a consequence, moving into a more senior role with more subordinates is an almost universal sign of increased responsibility. Accordingly, we found that $73 \%$ of the jobs in our data involved managing subordinates; among those job spells that began more than 10 years after graduation, more than $85 \%$ reported subordinates. For each job, we asked "what was the total number of people who worked in units that you managed when you first started this job?" We took the log of this value because it was highly skewed (because the log of zero subordinates is undefined, we first add one to each observation) and calculated the difference between consecutive jobs.

Hierarchical Rank. Respondents also provided job titles for each job. We used these job titles to develop a hierarchical rank code that we use to compare the title. This code approximates to: $1=$ specialist, $2=$ senior specialist, $3=$ manager, $4=$ senior manager, $5=\mathrm{VP} /$ director, $6=$ senior VP/director, 7 = C-level officer, $8=\mathrm{CEO}$. We refined this code to apply to different industries in slightly different ways (for example, vice presidents tend to be a fairly junior position in investment banking, but not in corporate jobs). We also surveyed current students about the hierarchy at their prior employers to fine

\footnotetext{
${ }^{2}$ We dropped the 16 moves that were coded as taking place due to a temporary job ending, and 2 where the worker left their job to return to school because we didn't view these as comparable with other kinds of moves.
} 
tune our understanding of ranks in consulting and investment banking.

There are important limitations to this measure because of the way that job titles vary across organizations and across industries. Despite these problems, there is enough systematic information in these titles to provide a useful complement to our subordinate-based measure of responsibilities. We tested the validity of the rank variable by regressing log subordinates and log earnings on rank, year that the job began, industry, function and log of organization size. Number of subordinates increased monotonically with rank, and including rank in the subordinate regression increased the variance explained from $21 \%$ to $34 \%$. Log earnings also increased monotonically with rank except for rank 8 , whose effect was slightly (and insignificantly, $\mathrm{p}<.89$ ) lower than rank 7. Adding rank to the regression increased the variance explained from $36 \%$ to $49 \%$. These analyses demonstrate the substantial information found in our measure of rank.

Change in log earnings. Respondents reported their total earnings in their first year in each job. We took the $\log$ of this value because of its high skew, and calculated the difference in log earnings between the first year of one job and the first year of the next, for consecutive jobs.

Function change. For each job, we asked respondents what function the job was in, offering 34 different responses in a drop down menu. ${ }^{3}$ We based our list of functions on those that students were likely to go into, as well as reviews of occupational categories in standardized surveys such as the Current Population Survey. We further revised the list after pilot testing the survey, and again after the survey to combine some of the smallest and most similar functions, giving us 27 different functions. Those functions are listed in the appendix. We code a move as involving a change in function when respondents report a different function in their current job to the one that they worked in in their prior job.

\section{Control Variables}

We include a number of control variables. We controlled for current and prior function and industry

\footnotetext{
${ }^{3}$ Respondents were only allowed to select a single function in our data; where some jobs already spanned multiple functions, changes in function reported may reflect shifts in emphasis between jobs as the most important function within jobs changed, rather than discrete shifts.
} 
because pay and responsibility often vary across kinds of jobs. Respondents were asked to choose the industry of each employer from a list of options. We devised our industry categories based on the distribution of industry affiliations in the school's alumni directory, providing more detailed categories in those areas in which students were more likely to work (mainly in the finance area). For some of our analyses, we collapsed these industries into 5 sectors that have similar work, career paths and rewards. These were: investment banking (13\%); investment management (11\%); consulting and accounting (19\%); other private businesses (54\%); and non-profit and government (4\%). Moves across these sectors should involve a substantially greater change in the nature of work than moves within the sectors.

We also control for current and past organizational size. For each employer, we asked "Counting all locations where this employer operated, what was the total number of persons who worked for this employer at the time that you took the job?" and asked them to choose from the set of: less than 10; 1049; 50-99; 100-499; 500-999; 1,000-4,999; 5,000-9,999; 10,000 - 49,999; 50,000-100,000; 100,000+ . For our analyses, we then converted this to a single log scale, taking the midpoint of each range and choosing a value of 150,000 for firms with more than 100,000 employees.

We also control for additional variables. First, we measured workers' post-MBA experience at the start of each job. Because the MBA represents a well-defined career stage, experience prior to the MBA has little effect on the level of jobs that students enter following the degree, at least for high status schools (Bonet 2008). Opportunities should therefore reflect post-MBA experience. Because the effects of that experience may be non-linear, we also included experience squared in our analyses (adding additional orders of experience did not affect our results). We also control for the length of time between the beginning of the current and prior job, because the difference between the pay and responsibilities of the current job and the prior one may depend in part on how much experience the worker obtained in that

\footnotetext{
${ }^{4}$ Pre-tests of the survey indicated that respondents had a great deal of difficulty giving an exact number of workers for their employers, but were much more able to pick within a range
} 
prior job ${ }^{5}$. Additionally, we controlled for worker gender (around 30\% of both respondents in our sample were women) and whether the respondent is an alumnus/a of the executive MBA program, which offers equivalent classroom training to the regular MBA but also admits more experienced students. We also include controls for change in hours between the current and prior jobs, in order to account for whether moves might have been seeking a reduction in work pressures. Finally, we control for prior rank, using dummy variables for each rank to account for non-linearities.

\section{RESULTS}

Table 1A provides means, standard deviations and correlations for all of our variables. The mean values show that $65 \%$ of the moves within our data take place within an organization, $26 \%$ take place voluntarily across organizations and $9 \%$ take place involuntarily across organizations. Table 1B provides another way of comparing the prevalence of internal and external mobility for more experienced workers. The table summarizes the number of employers and jobs held by each worker who graduated between 1990 and 1995 (we chose this subsample to examine how much workers moved over a span of 15-20 years). It demonstrates the high degree of mobility within this sample. Less than $2 \%$ of respondents had held the same job since graduating, and only $13 \%$ of the workers reported having worked for only one employer. Summing the diagonal elements also indicates that only $13 \%$ of workers reported only one job per employer. Over this time frame, then, almost all workers engaged in both internal and external mobility. We also examined the duration of job spells ending in internal versus external voluntary mobility, and found very similar means (792 days versus 739) and medians (548 days versus 565), suggesting that these shifts occur at similar times.

Table 1C provides further descriptive data, comparing our four main dependent variables across the different kinds of moves. As well as the logged values, we also include actual values for subordinates and earnings in order to aid interpretations. As well as showing the mean changes in each of these variables,

\footnotetext{
${ }^{5}$ Although this variable usually measures time in prior job, it may also include any gap between the end of the prior job and the beginning of the current one.
} 
we also provide the $10^{\text {th }}, 25^{\text {th }}, 50^{\text {th }}, 75^{\text {th }}$ and $90^{\text {th }}$ percentiles. Indeed, the very high skew of pay and subordinates suggests that differences in the means for those variables should be largely ignored.

This descriptive data provides strong support for our argument that internal and external moves play different roles in workers' careers. While internal moves provide substantial increases in log subordinates and rank, the average external move, either voluntary or involuntary, does not increase log subordinates and involves much smaller increases in rank. Nonetheless, we find that increases in log pay are quite similar between internal and external moves, particularly when those moves take place within the same function. These statistics also highlight the importance of mobility to increases in log pay. We estimate that workers' log pay in our sample increased by around 4-6\% per year when they stayed within their jobs. ${ }^{6}$ Table $1 \mathrm{C}$ demonstrates that the pay of workers who moved internally increased an average of $34 \%$ over the 2.2 years that it took them to get promoted (based on the log values); the pay of those who moved externally within the same function also increased by around 35\% over a period of 2.2 years. These forms of mobility therefore increased pay much more than did staying within the same job, at least over the short run.

\section{Multivariate Analyses}

Table 2 presents multivariate analyses of the determinants of changes in responsibilities, earnings and functions. The unit of analysis is a move between two jobs, and the dependent variables are the changes in subordinates, rank, earnings and function that took place on each change. Because $\mathrm{H} 2$ and $\mathrm{H} 4$ relate to differences across outcomes for internal versus external moves, we first standardized our dependent variables for changes in responsibilities and earnings. Each change variable (log subordinates, rank, log earnings) was subtracted from its global mean, and divided by its global standard deviation. This allowed us to compare the magnitude of effects across these measures, relative to the overall variability in these measures.

\footnotetext{
${ }^{6}$ These estimates were calculated by examining the difference between the pay that workers received in 2010 or the pay that they received in the last year with their employer on the one hand, and their pay in the year that they began that job on the other.
} 
The structure of our data means that we can have more than one observation per individual leading to non-independence of errors. We address this problem by implementing robust standard errors, clustered by respondent. Using differences in attributes of consecutive jobs as a dependent variable can also induce autocorrelation in errors. We therefore ran Prais-Winsten models which correct for these effects (Greene 2003), but found almost no effect on the results. An alternative approach to analyzing such nested data structures is to use hierarchical linear modeling, which includes a random effect for each respondent (Rabe-Hesketh and Skrondal 2008). We reran our analyses using such models, and again received almost identical results to those presented here. The use of such hierarchical methods also had limitations for our purposes: some of our hypotheses require cross-equation tests of coefficients which cannot be implemented in Stata using hierarchical linear models. We therefore present the simpler OLS models here (models 4 and 5 are logit models).

Changes in Responsibilities (H1). We first test H1 by comparing changes in responsibility for internal and external moves (Model 1 of Table 2). The key independent variables are the "external voluntary" and "external involuntary" variables - the excluded category is internal moves. Model 1 finds strong, negative, and significant coefficients of similar magnitudes for both voluntary and involuntary external moves, consistent with H1. Because the dependent variables have been standardized to allow cross-equation comparisons, the coefficients must be multiplied by the standard deviation of the dependent variable in order to calculate the effects size. Doing so (and then exponentiating the effect) indicates that that internal moves are associated with around a 59\% greater increase in subordinates than voluntary external moves.

One concern with this analysis is that firms may simply be reluctant to hire from outside into jobs that involve managing more people, if, for example, those jobs required more firm specific skills. We therefore reran the analysis controlling for current log subordinates. Such a specification effectively compares how many fewer subordinates the prior job had for internal versus external moves. We again found highly significant effects, although the coefficient for external voluntary moves was somewhat 
attenuated $(b=-.259, \mathrm{z}=-8.27)$. Given that this control is as much a consequence of the move as a confounding variable, we leave it out of our main analysis.

We then examine changes in rank in Model 2. We again find significant, negative coefficients for both voluntary and involuntary external moves, providing further support for H1. Multiplying the coefficient for voluntary external moves (-.18) by the standard deviation of rank difference (1.59) indicates that those external moves are associated with an increase in rank that is 0.29 steps smaller than internal moves, on average. In additional analysis, we explored whether external mobility is associated with more rapid subsequent promotions, but we found no evidence of such effects.

Effects on Pay (H2). H2a argued that external moves would be associated with smaller increases in pay than internal moves. Model 3 provides support for this hypothesis, demonstrating that both voluntary and involuntary external moves are associated with lower pay increases. Multiplying the coefficient for external voluntary moves (-.1) by the standard deviation of change in log pay (0.41) indicates that external voluntary moves are associated with an increase in pay that is $4 \%$ (of absolute pay) smaller than for internal moves. Pay raises for involuntary moves are $15 \%$ smaller.

$\mathrm{H} 2 \mathrm{~b}$ suggested that the pay difference between internal and external voluntary moves should be less than the difference in responsibilities, as firms paid outsiders to move even though they wouldn't promote them. We test this hypothesis in the bottom row of Table 2, which reports significance levels for the difference between the coefficient for external voluntary moves on pay versus our measures of responsibility (subordinates and rank). These cross-equation tests indicate that the coefficient for external voluntary moves is significantly smaller for pay than it is for subordinates (at the $p<.0000$ level), and marginally so for rank (at the $\mathrm{p}<.052$ level), largely supporting $\mathrm{H} 2 \mathrm{~b}$. Hence, while external voluntary moves are associated with much smaller increases in responsibility than internal moves, they receive much more similar increases in pay.

$\mathrm{H} 2 \mathrm{c}$ then argued that the pay differences between internal and external moves would be greater when external moves were involuntary. We test this hypothesis by comparing the coefficients on voluntary and 
involuntary external moves (second to last row of Table 2). We find that involuntary moves do indeed receive much lower pay increases than voluntary moves $(\mathrm{p}<0.0000)$. We further find that the difference between voluntary and involuntary moves is much greater for pay than for log subordinates, where there is no significant difference, and for rank, where the difference is significant by smaller in magnitude.

Changes in Job Function for External and Internal Moves (H3). Models 4 and 5 of Table 2 report the results of logit models estimating the odds that a move involves a change in functions. Consistent with H3, Model 4 demonstrates positive coefficients for external voluntary and involuntary moves, indicating that workers are more likely to change their function when they move externally. When we include a control for moves across sectors in Model 5, though, the coefficients for both kinds of external moves lose significance. These results indicate that external moves are more likely to involve a change in function, but only when those moves take workers into a substantially different industry. External moves within the same sector are no more or less likely to involve a change in function than are internal moves.

Interaction of Horizontal Shifts and Vertical Achievement (H4a and H4b). Finally, Models 6-8 test how the effects of internal and external moves change when moves also involve changes across function.

Models 6 and 7 test H4a, that the differences in changes in responsibilities between internal and external moves will be smaller when those moves also involve a shift across functions. We find limited support for the hypothesis. The only fully significant result is the interaction between involuntary external mobility and function change in model 7.

Model 8 then tests $\mathrm{H} 4 \mathrm{~b}$, that external voluntary moves will receive lower pay increases when they also involve a move across functions. Consistent with our arguments, the differences in pay increases for external voluntary versus internal moves is significantly less when those moves also involve a shift across functions (Model 8). ${ }^{7}$ Indeed, the main effect of external voluntary moves on pay becomes insignificant

\footnotetext{
${ }^{7}$ An alternative explanation for the reduced pay that workers receive on moving functions and firms simultaneously is that those moves are likely to be across industries, and workers' skills are less applicable in new industries (Sturman et al. 2008). The fact that the change in pay falls substantially more than the change in
} 
in Model 8: there is no difference between the pay received for internal and external voluntary moves when the external moves take place within the same function - even though such moves see substantial differences in the responsibilities that workers take on. We also see that the main effect of external voluntary moves on pay is significantly smaller than its main effect on rank and responsibilities, providing strong support for $\mathrm{H} 2 \mathrm{~b}$ when moves take place within a function.

\section{Supplementary Analyses}

Robustness Checks. In supplementary analyses (available from the authors), we explored how our results might vary across different subsamples of the data. We ran the analyses separately for each of the five industry sectors of investment banking, consulting, investment management, other private business, and government and non-profit, finding substantively similar results for all sectors except government and non-profit (representing around $4 \%$ of our sample). In each case, internal shifts had significantly higher increases in responsibility than external shifts, and the change in pay was smaller than the change in responsibilities (although the difference was not always significant, reflecting smaller sample sizes. Interaction effects were often not significant either). We also split the sample by gender, and found a similar pattern of results for men and women. We also tried restricting our sample to moves made between 2008 and 2011, to test whether the severe recession affected the relationships in our results. We found, though, that the results in this subsample were qualitatively very similar to those in the overall analysis. Our results were also similar when we restricted external moves first to those that remained within the same sector and then to moves that went across sectors. We did find, though, that the interaction between external moves and functional changes did not significantly affect pay when moves took place within sector. This may be because moves within sector could also have taken place within the prior organization, even when they involve a functional shift.

As a further robustness check, we reran the analyses in Table 2 using individual fixed effects. Those

responsibilities on those cross-function moves suggests that the effect is not simply due to a lack of applicable skills, which would also show up in an inability to obtain a high level of responsibilities. 
analyses effectively introduce a separate dummy variable for each individual, allowing us to compare whether individuals who make some internal moves and some external moves receive similar gains from each. Those analyses demonstrated very similar results to those found in the pooled cross-sectional analysis in Table 2, although the interaction effect between functional change and external voluntary moves was no longer significant in the pay regression. This analysis indicates that the same people experience very different outcomes when they move internally versus externally. Our main results, are not, therefore driven by differences in workers' underlying proclivities to move jobs within versus across firms, or by fixed differences in their loyalties to their employers.

Longer term career outcomes. Although our theory focuses on the immediate effect of mobility, we also explored how those effects might cumulate by examining how workers' earnings in 2010 and career satisfaction at the time of the survey were related to the number of internal and external moves they had made previously. These analyses are presented in Table 3 . There are many ways to measure career success, and workers may opt for less rewarding jobs at some points of their careers. These data also provide just a single snapshot at one point in time. These measures nonetheless provide data on the longer run consequences of mobility. We restricted the data to respondents who graduated between 1990 and 2005 in order to allow time for meaningful movement across jobs, and to those who gave us details of every job move that they had made as well as their current earnings. We also dropped respondents who were outside the US at the time (around $20 \%$ of the sample) whose responses may not have been given in dollars. ${ }^{8}$ Our main variables are the total numbers of moves of each type that workers have made. We control for experience and experience squared in order to take account of the fact that workers who graduated at different times have had different opportunities to move, and will be at different stages in their careers. We also control for when the current job started, as pay tends to rise within jobs, and for the number of spells spent in unemployment or out of the workforce for family reasons. We also control for

\footnotetext{
${ }^{8}$ As a robustness check, we replicated our main analyses dropping external moves across countries in case currency differences might affect our results. This exclusion did not substantially affect our results.
} 
initial industry and function, on the basis that different career tracks have very different pay, but current industry and function may be endogenous to the moves workers have made.

The Table indicates that the number of internal moves to date made by a worker is positively and significantly associated with higher pay (around 3\% more pay per move). The number of involuntary external moves is negatively and significantly associated with pay. The number of voluntary external moves, though, has no significant association with pay.

We find similar results for career satisfaction, which we measured using a five item scale devised by Greenhaus, Parasuraman and Wormley (1990) containing items such as "I am satisfied with the progress I have made towards meeting my overall career goals" $(\alpha=0.90)$. Again, larger numbers of internal moves are associated with higher career satisfaction, involuntary external moves have negative effects, and there is no effect of voluntary external moves.

Although internal and external moves play different roles in workers' careers, these results suggest that internal moves have greater advantages. Although external voluntary moves provide immediate pay increases, it may be that those increases are not sustainable without an accompanying increase in responsibilities. By providing both increased responsibilities and increased pay, internal moves appear to advantage workers more over the long term.

Predicting Internal and External Moves: Although the central focus of this paper is on the different consequences associated with internal and external moves, we also ran exploratory analyses to understand when workers are more likely to engage in one kind of move over another. Those analyses are presented in Table 4, which reports results of multinomial logit analyses of mobility outcomes. The unit of analysis is a year spent in a job. The four possible outcomes are "no change" (stay in the job), "internal move", “external voluntary move", and "external involuntary move". We include controls for time spent in the job and time spent in the job squared to account for time dependence of mobility. Model 1 explores basic time dependence of mobility. Model 2 then adds job characteristics. Internal moves are the excluded category in the Table. 
A striking finding from the table is that for many variables (e.g. time in job, log firm size, and seniority as measured by rank and number of subordinates), the determinants of voluntary external mobility are very similar to the determinants of not moving. Many of these variables relate to the availability of vacancies for movement within an organization: such vacancies should be more common when organizations are larger and workers are more junior, meaning that there are more higher level jobs to move into. We have argued and shown that internal mobility is more likely to be associated with vertical advancement than external mobility. The pattern of findings in this table is also consistent with such a finding: one interpretation is that internal mobility is generally a preferred option for workers, so that external mobility is more likely under those conditions when workers find it more difficult to move internally. We also find that external voluntary moves are more likely out of low paid jobs, underscoring that workers are more likely to move externally if jobs in the current organization are not attractive.

Some of the non-findings in Table 4 are also interesting. If the workers who move externally are mainly those who do not expect to be promoted internally, then the "Peter principle" suggests that workers might first move internally until their responsibilities matched the ceiling of their ability, before making subsequent moves across firms. Model 2 provides little evidence of such an effect: once we control for the position a worker is in, there is no effect of the number of jobs that a worker has had on the relative probability of internal versus external mobility. The coefficients on experience also indicate that the probability of voluntary external mobility relative to internal peaks after only 5 years. Voluntary external moves happen throughout the careers in our sample, and not just during the later stages.

We should also note that the overall predictive power of Table 4 is low. Based on Model 2, the estimated mean probability of making a voluntary external move in a given year was $8.4 \%$ in years where such moves actually took place, versus an overall average of $6.3 \%$. Similarly, the estimated mean probability of moving internally was $21 \%$ in years where internal moves actually took place versus an overall mean of $14 \%$. The model therefore leaves much mobility unexplained. Some of the variation in internal versus external moves may reflect differences in how much people like their employer; people 
who feel they are a poor fit for the organization will be more likely to move to another firm (O'Reilly et al. 1991). That said, the fact that their new employers still offer a substantial pay raise suggests that this is not the only motivation underlying lateral moves. We also suspect that whether a given move takes

place internally or externally is strongly shaped by the largely random arrival of opportunities, such as having a higher level vacancy open when a worker is ready to be promoted, or being contacted by a headhunter at a time when internal opportunities look scarce.

\section{DISCUSSION}

Today's careers increasingly combine moves between jobs both within firms and across firms. This study applies matching theory to develop new predictions about the different consequences for workers of those internal and external job moves. We test those predictions in a sample of MBA alumni. Most of our respondents moved jobs both within and across firms as their careers unfolded. Yet those internal and external moves played substantially different roles within their careers.

The internal moves that we studied were strongly associated with upwards progression into jobs with more responsibility. Of the internal moves in our data, $62 \%$ involved an increase in numbers of subordinates managed. By contrast, only $36 \%$ of voluntary external moves and $31 \%$ of involuntary moves involved similar increases in responsibility. Put another way, $77 \%$ of the moves in our sample that increased the number of subordinates managed took place within organizations. These differences support our arguments that employers are prepared to promote their own employees if they are performing well, but are reluctant to hire an external worker, whom they know much less about, into a job with more responsibilities than they currently hold. Although we argued that these advantages of internal mobility would be muted during functional moves, we found little evidence for such an effect. While workers have become more likely to move across firms in recent decades (Bidwell 2013; Hollister 2011) and scholars have become increasingly interested in the "boundaryless" nature of careers (Arthur and Rousseau 1996), for the population that we studied, it was the traditional career moves within organizations that were more likely to lead to advancement. 
While external moves did not allow workers to increase their responsibilities in the same way that internal moves did, they were associated with other benefits. Voluntary external moves were often accompanied by substantial pay increases, similar to those found in internal moves, despite involving much less advancement in responsibilities. External moves into substantially different industries were more likely to take our respondents into different job functions, potentially allowing them to find jobs that better fit their preferences. These cross-function voluntary external moves were not accompanied by the same kinds of pay raises as within-function moves; nor were involuntary external moves. Instead, change in pay, changes in horizontal fit, and need to find a new job seem to act as substitutes in inducing workers to move firms.

Our supplementary results suggest that these differences in the immediate effects of moves have lasting consequences. Workers who had engaged in more internal moves ended up earning higher salaries and expressing greater career satisfaction at the time of our survey, while the number of voluntary external moves had no effect (involuntary moves had a substantial negative effect). While both internal and voluntary external moves lead to immediate pay gains, it appears that only the gains experienced in internal moves, accompanied as they are by increases in responsibilities, are sustainable in the long term.

Our results therefore suggest the image of careers as a series of ladders within organizations, linked by lateral shifts across organizations. Most workers engage in both internal and external mobility, but those moves play different roles in their careers. Internal mobility is the dominant means by which workers climb the career ladder, moving into jobs with increased responsibilities. External mobility is less likely to lead up the ladder of responsibility, but leads instead to sideways shifts from one ladder to the next, arriving at a similar rung, albeit in different work or for more pay.

This study has a number of limitations. First, it is unclear how our results would generalize beyond managerial jobs and the elite workers that we study here. The effects of internal and external mobility may, for example, be different among those who are less likely to follow orderly careers of vertical advancement than are MBA alumni, or who have less human capital. The basic principles of our 
arguments are intended to apply broadly in labor markets where career progression and upward mobility are an important part of careers. How well they do so remains an empirical question.

Another challenge in this kind of work is measuring internal mobility in a way that allows for a direct comparison with external mobility. We provided survey respondents with a clear definition of mobility that encompassed the major elements of changes in jobs - changes in responsibilities, functions and organizational context - but it is possible that respondents were nonetheless more likely to code promotions as job changes compared to lateral moves. The fact that both internal and external mobility occurred after very similar amounts of time in the job gives us some reassurance that they represent similarly substantial shifts in workers' careers, and the balance between vertical and lateral moves in our data is consistent with research using investment banking personnel data (Bidwell 2011), an industry similar to many of those in our sample. Even were our study to undercount levels of lateral mobility within organizations, it would remain the case that the overwhelming majority of upward mobility in this population took place during internal moves. Our measures of voluntary versus involuntary mobility may also misclassify some moves, such as those made voluntarily but in the face of a likely dismissal. Nonetheless, the sharp differences in pay increases received during voluntary and involuntary moves suggest that our measure is able to meaningfully differentiate between moves.

Our study also has implications for future work. We have focused on how different kinds of moves affect objective outcomes (Peiperl and Gunz 2007). Complementary work could explore how internal versus external moves are subjectively experienced by workers. Future work could also explore different measures of responsibilities, given the limitations in ours. It is likely, for example, that some increases in responsibility occurred without increasing the number of subordinates managed (Gunz 1989). The difficulty of comparing job titles across organizations and industries also makes our hierarchical rank measure inherently noisy. We can take some comfort in the consistent results across those measures, as well as our checks on the validity of each measure. Another interesting topic for future studies is to examine not just jobs taken, but also the offers workers received, both internally and externally. Such 
studies would allow us to better separate out employer and worker actions (Fernandez and Sosa 2005) and allow us to explore whether internal promotions are ever a response to external offers. Relatedly, it would also be valuable to explore which moves are taken at the initiative of the worker versus employer, both within and between firms.

While we demonstrate the different roles that internal and external mobility play in workers' careers, we do not place a causal interpretation on those effects. We are interested in whether workers are finding the same kinds of opportunities for advancement through external mobility and internal mobility. We find that they are not. Indeed, we expect that the anticipated gains that workers will receive from internal versus external mobility will partly affect when they engage in each. Our main analyses suggest advantages to internal mobility, in that it is more likely to allow workers to move into higher level jobs. Our supplementary analyses of when workers engage in external and internal mobility are consistent with internal mobility often being preferred by workers, with workers more likely to move externally when possibilities for internal mobility are more limited. Such effects make the decoupling of responsibilities and pay on moving externally all the more surprising: if external employers expected that only those workers who lacked internal opportunities would be prepared to move, they might feel less need to offer them such large pay raises. More generally, we believe that there is scope for further research to understand when workers are more likely to engage in each of these kinds of moves.

We believe that this analysis contributes substantially to our understanding of modern careers. Although many scholars have pointed to the combination of internal and external mobility that characterizes modern careers (Cappelli and Hamori 2005; le Grand and Tahlin 2002; Valcour and Tolbert 2003), prior work has not developed a clear theoretical basis for comparing their effects on workers' careers. We develop such a perspective and show for the first time how internal versus external mobility are associated with very different changes in responsibility, but often have similar effects on pay. We contribute particularly to the literature on boundaryless careers (Arthur and Rousseau 1996; Inkson et al. 2012). We show that while careers regularly cross firm boundaries, those boundaries matter: moves that 
take place within them are very different to the moves that take place across them. A particular consequence is that moves across firm boundaries rarely advance careers by increasing responsibilities.

This research also contributes to our broader understanding of external worker mobility. Although turnover is well studied (e.g. Hom and Kinicki 2001; Hom et al. 2012), very little research has explored the kinds of jobs that workers move to and from (but see Hamori's (2010) comparison of the titles of workers moving across firms, using a headhunter database). To our knowledge, this is the first study to explicitly compare the responsibilities of the jobs that workers move between as they move firms, using a systematic sample and drawing on data on both job titles and people managed. In doing so, we are able to demonstrate some key features of that external mobility, in ways that can inform the literature on turnover. In part, we show that mobility is overwhelmingly lateral, with moves into jobs with more responsibilities being comparatively rare among external moves. This suggests that direct career advancement may rarely be a motivator for turnover. In part, we also provide a lens for examining the heterogeneity in that mobility, showing that the consequences of external moves are different depending on whether they take workers into different functions. These findings raise the question of whether different kinds of external moves have different determinants.

Our study also contributes to our understanding of involuntary mobility. Much work has documented the declines in pay that accompany involuntary separation (e.g. Gibbons and Katz 1991; von Wachter and Bender 2006). Although we echo those findings, we generally find smaller results for changes in responsibilities. This pattern of results raises the possibility that a key disadvantage for downsized workers is their inability to wait for an attractive offer and bargain effectively. We also extend internal labor market models of worker mobility. Those models examined how workers' careers unfolded within organizations through the climbing of specific job ladders and moves between those ladders (DiPrete 1987; Stewman and Yeh 1991). We show how the same logic can be extended to the labor market as a whole, with job ladders largely existing within firms, and lateral moves frequently taking place between firms. 
Finally, our results also lend themselves to some clear career advice. We show how upwards mobility is easier within organizations than across them. Workers looking to build a career of upwards mobility, moving into jobs with increased responsibility and the associated power and prestige, are more likely to be able to do so through internal advancement. Those workers would therefore be well advised to choose jobs which offer better opportunities for subsequent advancement within the organization, rather than those from which the main scope for advancement requires a move to another firm. 


\section{REFERENCES}

Arthur, M.B., D.M. Rousseau. 1996. The boundaryless career : a new employment principle for a new organizational era. Oxford University Press, New York.

Baker, G., M. Gibbs, B. Holmstrom. 1994. The Internal Economics of the Firm: Evidence from Personnel Data. The Quarterly Journal of Economics 109(4) 881-919.

Bertrand, M., C. Goldin, L.F. Katz. 2009. Dynamics of the gender gap for young professionals in the corporate and financial sectors. Unpublished Manuscript.

Bidwell, M.J. 2011. Paying More to Get Less: Specific Skills, Incomplete Information and the Effects of External Hiring versus Internal Mobility. Administrative Science Quarterly 56(3) 369-407.

Bidwell, M.J. 2013. What happened to long term employment? The role of worker power and environmental turbulence in explaining declines in worker tenure.

Bidwell, M.J., F.S. Briscoe. 2010. The Dynamics of Inter Organizational Careers. Organization Science 21(5) 1034-1053.

Bidwell, M.J., J.R. Keller. 2014. Within or without? How firms combine internal and external labor markets to fill jobs. Academy of Management Journal 57.

Bills, D.B. 1990. Employers Use of Job History Data for Making Hiring Decisions - a Fuller Specification of Job Assignment and Status Attainment. Sociological Quarterly 31(1) 23-35.

Bonet, R. 2008. Opening the Black-Box of Individuals' Career Advancement: The Role of Organizational Factors, University of Pennsylvania, Philadelphia.

Campbell, B.A., M. Ganco, A.M. Franco, R. Agarwal. 2012. Who leaves, where to, and why worry? employee mobility, entrepreneurship and effects on source firm performance. Strategic Management Journal 33(1) 65-87.

Cappelli, P. 1999. The new deal at work : managing the market-driven workforce. Harvard Business School Press, Boston.

Cappelli, P., M. Hamori. 2005. The New Road to the Top. Harvard Business Review 83(1) 25-32.

Chan, W. 2006. External Recruitment and Intrafirm Mobility. Economic Inquiry 44(1) 169-184.

Cohen, L.E. 2013. Assembling jobs: A model of how tasks are bundled into and across jobs. Organization Science.

Cycyota, C.S., D.A. Harrison. 2006. What (Not) to Expect When Surveying Executives: A Meta-Analysis of Top Manager Response Rates and Techniques Over Time. Organizational Research Methods 9 133160.

DiPrete, T.A. 1987. Horizontal and Vertical Mobility in Organizations. Administrative Science Quarterly 32(3) 422-444.

Dobrev, S.D. 2012. Career Change and the Iron Cage: Organizations and the Early Labour Market Experience of Professional Managers. Journal of Management Studies 49(5) 843-868.

Doeringer, P.B., M.J. Piore. 1971. Internal labor markets and manpower analysis. Heath, Lexington, Mass.,.

Dokko, G., L. Rosenkopf. 2010. Social capital for hire? Mobility of technical professionals and firm influence in wireless standards committees. Organization Science 21(3) 677-695.

Dreher, G.F., T.H. Cox, Jr. 2000. Labor Market Mobility and Cash Compensation: The Moderating Effects of Race and Gender. The Academy of Management Journal 43(5) 890-900. 
Fernandez, R.M., M.L. Sosa. 2005. Gendering the Job: Networks and Recruitment at a Call Center. The American Journal of Sociology 111(3) 859-904.

Gibbons, R., L.F. Katz. 1991. Layoffs and Lemons. Journal of Labor Economics 9(4) 351-380.

Greene, W.H. 2003. Econometric analysis, 5th ed. Prentice Hall, Upper Saddle River, NJ.

Greenhaus, J.H., S. Parasuraman, W.M. Wormley. 1990. Effects of Race on Organizational Experiences, Job Performance Evaluations, and Career Outcomes. The Academy of Management Journal 33(1) 64-86.

Greenwald, B.C. 1986. Adverse Selection in the Labour Market. The Review of Economic Studies 53(3) 325-347.

Griffeth, R.W., P.W. Hom, S. Gaertner. 2000. A meta-analysis of antecedents and correlates of employee turnover: update, moderator tests, and research implications for the next millenium. Journal of Management 26(3) 463-488.

Groves, R.M., E. Peytcheva. 2008. The impact of nonresponse rates on nonresponse bias. Public Opinion Quarterly 72(2) 167-189.

Groysberg, B. 2010. Chasing Stars: The myth of talent and the portability of performance. Princeton University Press, Princeton, NJ.

Gunz, H. 1989. Careers and corporate cultures: Managerial mobility in large corporations. Basil Blackwell Ltd., Oxford.

Hamori, M. 2010. Who gets headhunted - and who gets ahead? The impact of search firms on executive careers. Academy of Management Perspectives 24(4) 46-59.

Heckman, J.J., G. Sedlacek. 1985. Heterogeneity, Aggregation, and Market Wage Functions - an Empirical-Model of Self-Selection in the Labor-Market. Journal of Political Economy 93(6) 1077-1125.

Hollister, M.N. 2011. Employment stability in the US labor market: Rhetoric vs Reality. Annual Review of Sociology 37(1) 305-324.

Hom, P.W., A.J. Kinicki. 2001. Toward a Greater Understanding of How Dissatisfaction Drives Employee Turnover. The Academy of Management Journal 44(5) 975-987.

Hom, P.W., T.R. Mitchell, T.W. Lee, R.W. Griffeth. 2012. Reviewing Employee Turnover: Focusing on Proximal Withdrawal States and an Expanded Criterion. Psychological Bulletin 138(5) 831-858.

Inkson, K., H. Gunz, S. Ganesh, J. Roper. 2012. Boundaryless Careers: Bringing Back Boundaries. Organization Studies 33(3) 323-340.

Jovanovic, B. 1979. Job Matching and the Theory of Turnover. The Journal of Political Economy 87(5) 972-990.

le Grand, C., M. Tahlin. 2002. Job Mobility and Earnings Growth. European Sociological Review 18(4) 381-400.

Lee, T.W., T.R. Mitchell. 1994. An Alternative Approach: The Unfolding Model of Voluntary Employee Turnover. The Academy of Management Review 19(1) 51-89.

Logan, J.A. 1996. Opportunity and choice in socially structured labor markets. American Journal of Sociology 102(1) 114-160.

Marler, J.H., M.W. Barringer, G.T. Milkovich. 2002. Boundaryless and traditional contingent employees: worlds apart. Journal of Organizational Behavior 23 425-453.

McCue, K. 1996. Promotions and Wage Growth. Journal of Labor Economics 14(2) 175-209. 
Mollick, E. 2012. People and Process, Suits and Innovators: The Role of Individuals in Firm Performance. Strategic Management Journal.

O'Mahony, S., B.A. Bechky. 2006. Stretchwork: Managing the career progression paradox in external labor markets. Academy of Management Journal 49(5) 918-941.

O'Reilly, C.A.I., J. Chatman, D.F. Caldwell. 1991. People and Organizational Culture: A Profile Comparison Approach to Assessing Person-Organization Fit. The Academy of Management Journal 34(3) 487-516.

Peiperl, M., H. Gunz. 2007. Taxonomy of Career Studies. H. Gunz, M. Peiperl, eds. Handbook of Career Studies. Sage, Thousand Oaks, CA.

Rabe-Hesketh, S., A. Skrondal. 2008. Multilevel and Longitudinal Modeling Using Stata. Stata Press, College Station, Texas.

Rosenbaum, J.E. 1979. Tournament Mobility: Career Patterns in a Corporation. Administrative Science Quarterly 24(2) 220-241.

Scott, W.R. 2003. Organizations : rational, natural, and open systems, 5th ed. Prentice Hall, Englewood Cliffs, N.J.

Sorensen, A.B. 1977. The Structure of Inequality and the Process of Attainment. American Sociological Review 42(6) 965-978.

Stewman, S., S.L. Konda. 1983. Careers and Organizational Labor Markets: Demographic Models of Organizational Behavior. The American Journal of Sociology 88(4) 637-685.

Stewman, S., K.S. Yeh. 1991. Structural Pathways and Switching Mechanisms for Individual Careers. Research in Social Stratification and Mobility 10 133-168.

Sturman, M.C., K. Walsh, R.A. Cheramie. 2008. The Value of Human Capital Specificity Versus Transferability. Journal of Management 34(2) 290-316.

Tolbert, P.S. 1996. Occupations, organizations and boundaryless careers. M.B. Arthur, D.M. Rousseau, eds. The boundaryless career: a new employment principle for a new organizational career. Oxford University Press, Oxford, 331-349.

Topel, R.H., M.P. Ward. 1992. Job Mobility and the Careers of Young Men. The Quarterly Journal of Economics 107(2) 439-479.

Valcour, P.M., P.S. Tolbert. 2003. Gender, family and career in the era of boundarylessness: determinants and effects of intra- and inter-organizational mobility International Journal of Human Resource Management. Routledge, 768-787.

von Wachter, T., S. Bender. 2006. In the Right Place at the Wrong Time: The Role of Firms and Luck in Young Workers' Careers. The American Economic Review 96(5) 1679-1705.

Waldman, M. 1984. Job Assignments, Signaling, and Efficiency. Rand Journal of Economics 15(2) 255267.

Weeden, Kim A. 2002. Why Do Some Occupations Pay More than Others? Social Closure and Earnings Inequality in the United States. American Journal of Sociology 108(1) 55-101.

White, H.C. 1970. Chains of Opportunity: System Models of Mobility in Organizations. Harvard University Press, Cambridge, MA.

Williamson, O.E., M.L. Wachter, J.E. Harris. 1975. Understanding the Employment Relation: The Analysis of Idiosyncratic Exchange. The Bell Journal of Economics 6(1) 250-278. 
TABLE 1A: SUMMARY STATISTICS

\begin{tabular}{|c|c|c|c|c|c|c|c|c|c|c|c|c|c|c|c|c|c|}
\hline & Mean & S.D. & 1 & 2 & 3 & 4 & 5 & 6 & 7 & 8 & 9 & 10 & 11 & 12 & 13 & 14 & 15 \\
\hline 1 Change in log subs & 0.43 & 1.33 & 1 & & & & & & & & & & & & & & \\
\hline 2 Change in rank & 0.83 & 1.59 & 0.23 & 1 & & & & & & & & & & & & & \\
\hline $\begin{array}{ll} & \text { Change in log } \\
3 & \text { earnings }\end{array}$ & 0.25 & 0.41 & 0.17 & 0.14 & 1 & & & & & & & & & & & & \\
\hline 4 Ext vol move & 0.26 & 0.44 & -0.17 & -0.04 & -0.06 & 1 & & & & & & & & & & & \\
\hline 5 Ext invol move & 0.09 & 0.28 & -0.13 & -0.08 & -0.16 & -0.18 & 1 & & & & & & & & & & \\
\hline 6 Log firm size & 8.39 & 2.96 & 0.06 & -0.06 & 0.03 & -0.17 & -0.14 & 1 & & & & & & & & & \\
\hline 7 Prior log firm size & 8.62 & 2.81 & -0.01 & -0.03 & -0.04 & -0.06 & -0.14 & 0.72 & 1 & & & & & & & & \\
\hline 8 Experience & 5.39 & 3.84 & -0.06 & -0.17 & 0.02 & -0.02 & 0.05 & -0.02 & -0.02 & 1 & & & & & & & \\
\hline 9 Exp squared & 43.79 & 62.40 & -0.05 & -0.15 & 0.01 & -0.03 & 0.04 & -0.03 & -0.02 & 0.95 & 1 & & & & & & \\
\hline 0 Time since last job & 2.13 & 1.51 & 0.04 & 0.06 & 0.25 & -0.03 & -0.01 & 0.01 & 0.02 & 0.44 & 0.41 & 1 & & & & & \\
\hline 1 Female & 0.28 & 0.45 & -0.04 & -0.02 & -0.09 & -0.02 & -0.04 & 0.09 & 0.08 & -0.05 & -0.05 & -0.03 & 1 & & & & \\
\hline 2 EMBA & 0.05 & 0.21 & 0.02 & -0.05 & -0.01 & -0.02 & 0.01 & -0.01 & -0.02 & 0 & 0 & 0.03 & -0.06 & 1 & & & \\
\hline 3 Year & 2004 & 4.93 & -0.06 & -0.06 & -0.04 & -0.01 & 0.01 & 0.01 & 0.02 & 0.3 & 0.29 & 0.12 & 0.08 & 0.07 & 1 & & \\
\hline 4 Last rank & 3.14 & 1.69 & -0.1 & -0.54 & -0.05 & 0.02 & 0.07 & -0.06 & -0.08 & 0.52 & 0.1 & 0.44 & -0.07 & 0.12 & 0.20 & 1 & \\
\hline Change in hours & -1.19 & 10.06 & 0.17 & -0.06 & 0.13 & -0.1 & -0.09 & 0.01 & 0.01 & 0.01 & 0.02 & -0.07 & -0.03 & 0.04 & -0.04 & .06 & 1 \\
\hline 6 Change in function & 0.40 & 0.49 & -0.08 & -0.07 & -0.17 & 0.21 & 0.11 & -0.03 & 0.02 & 0 & -0.01 & -0.07 & 0 & 0 & -0.01 & 07 & -0.08 \\
\hline
\end{tabular}


TABLE 1B: TOTAL EMPLOYERS AND JOBS FOR WORKERS WHO GRADUATED

BETWEEN 1990 AND 1995

\begin{tabular}{|l||l|l|l|l|l|l|l|l|l|l||l|}
\hline \multicolumn{9}{|c||}{} & \multicolumn{9}{|c||}{ Total number of employers } & \\
\hline Total jobs & $\mathbf{1}$ & $\mathbf{2}$ & $\mathbf{3}$ & $\mathbf{4}$ & $\mathbf{5}$ & $\mathbf{6}$ & $\mathbf{7}$ & $\mathbf{8}$ & $\mathbf{9}$ & Total \\
\hline $\mathbf{1}$ & 4 & & & & & & & & & 4 \\
\hline $\mathbf{2}$ & 6 & 13 & & & & & & & & 19 \\
\hline $\mathbf{3}$ & 8 & 6 & 8 & & & & & & & 22 \\
\hline $\mathbf{4}$ & 21 & 15 & 7 & 5 & & & & & & 48 \\
\hline $\mathbf{5}$ & & 14 & 10 & 7 & 3 & & & & & 34 \\
\hline $\mathbf{6}$ & & 10 & 19 & 14 & 3 & 4 & & & & 46 \\
\hline $\mathbf{7}$ & & 8 & 15 & 11 & 9 & 7 & & & & 47 \\
\hline $\mathbf{8}$ & & 2 & 7 & 4 & 10 & 3 & 3 & 1 & & 30 \\
\hline $\mathbf{9}$ & & 3 & 5 & & 4 & 1 & 3 & & & 19 \\
\hline $\mathbf{1 0}$ & & & 4 & 4 & 5 & 2 & 1 & & & 17 \\
\hline $\mathbf{1 1}$ & & & & 1 & 2 & 1 & & & 1 & 7 \\
\hline $\mathbf{1 2}$ & 1 & & 1 & & & & & & & 3 \\
\hline $\mathbf{1 3}$ & & & & & & & 1 & & & 1 \\
\hline $\mathbf{1 4}$ & & & 1 & & & & & & & 1 \\
\hline $\mathbf{1 5}$ & & & & & & 1 & & & & 1 \\
\hline $\mathbf{1 6}$ & & & & & & & 1 & & & 1 \\
\hline Total & 40 & 71 & 77 & 46 & 36 & 19 & 9 & 1 & 1 & 300 \\
\hline
\end{tabular}

Numbers in each cell represents number of workers who had held that many jobs at that many employers between graduating the MBA and responding to the survey. 
TABLE 1C: CHANGES IN RESPONSIBILITIES AND REWARDS. COMPARISON OF DIFFERENT TYPES OF MOVES

\begin{tabular}{|c|c|c|c|c|c|c|c|c|c|}
\hline Dependent Variable & Type of Move & Mean & Std. Dev. & $\begin{array}{l}\text { 10th } \\
\text { pctile }\end{array}$ & $\begin{array}{l}\text { 25th } \\
\text { pctile }\end{array}$ & Median & $\begin{array}{l}\text { 75th } \\
\text { pctile }\end{array}$ & $\begin{array}{l}\text { 90th } \\
\text { pctile }\end{array}$ & Count \\
\hline \multirow{6}{*}{ Change in subordinates } & Internal & 41.35 & 1464.36 & -1 & 0 & 2 & 5 & 25 & 3641 \\
\hline & Internal same f'n & 33.13 & 1693.52 & 0 & 0 & 2 & 5 & 16 & 2534 \\
\hline & External vol & -7.37 & 471.14 & -9 & -2 & 0 & 2 & 12 & 1428 \\
\hline & External vol same f'n & -6.96 & 647.38 & -10 & -1 & 0 & 2 & 13 & 615 \\
\hline & External invol & 21.72 & 498.52 & -13 & -2 & 0 & 1 & 7 & 479 \\
\hline & External invol same f'n & 61.1 & 757.47 & -11 & -2 & 0 & 1 & 10 & 204 \\
\hline \multirow{6}{*}{$\begin{array}{l}\text { Change in log } \\
\text { subordinates }\end{array}$} & Internal & 0.65 & 1.24 & -0.31 & 0.00 & 0.51 & 1.25 & 1.97 & 3641 \\
\hline & Internal same f'n & 0.67 & 0.99 & 0.00 & 0.00 & 0.59 & 1.10 & 1.79 & 2534 \\
\hline & External vol & $0.04 * * *$ & 1.40 & -1.61 & -0.61 & 0.00 & 0.69 & 1.61 & 1428 \\
\hline & External vol same f'n & $0.06^{* * *} *$ & 1.21 & -1.39 & -0.29 & 0.00 & 0.66 & 1.26 & 615 \\
\hline & External invol & $-0.12 * * *$ & 1.37 & -1.79 & -0.69 & 0.00 & 0.51 & 1.39 & 479 \\
\hline & External invol same f'n & $-0.04 * * *$ & 1.29 & -1.79 & -0.51 & 0.00 & 0.51 & 1.09 & 204 \\
\hline \multirow[t]{6}{*}{ Change in rank } & Internal & 0.93 & 1.41 & 0 & 0 & 1 & 2 & 2 & 3641 \\
\hline & Internal same f'n & $1.07 * * *$ & 1.34 & 0 & 0 & 1 & 2 & 3 & 2534 \\
\hline & External vol & $0.72 * * *$ & 1.88 & -2 & 0 & 0 & 2 & 3 & 1428 \\
\hline & External vol same f'n & $0.52 * * *$ & 1.55 & -1 & 0 & 0 & 1 & 2 & 615 \\
\hline & External invol & $0.40 * * *$ & 1.81 & -2 & -1 & 0 & 2 & 3 & 479 \\
\hline & External invol same f'n & $0.17 * * *$ & 1.54 & -2 & 0 & 0 & 1 & 2 & 204 \\
\hline \multirow[t]{6}{*}{ Change in earnings } & Internal & 92793 & 565760 & 4000 & 15000 & 30000 & 80000 & 200000 & 3641 \\
\hline & Internal same f'n & 106350 & 613663 & 5000 & 15000 & 40000 & 100000 & 230000 & 2534 \\
\hline & External vol & $66695 \dagger$ & 290267 & -30000 & 0 & 25000 & 70000 & 180000 & 1428 \\
\hline & External vol same f'n & 112380 & 379058 & -50000 & 10000 & 36250 & 100000 & 275000 & 615 \\
\hline & External invol & $-21910 * * *$ & 695985 & -75000 & -20000 & 8000 & 40000 & 102000 & 479 \\
\hline & External invol same f'n & $7509^{*}$ & 181269 & -90000 & -15000 & 10000 & 50000 & 105000 & 204 \\
\hline \multirow[t]{6}{*}{ Change in log earnings } & Internal & 0.30 & 0.35 & 0.03 & 0.11 & 0.22 & 0.41 & 0.69 & 3641 \\
\hline & Internal same f'n & $0.33 * * *$ & 0.36 & 0.06 & 0.13 & 0.24 & 0.41 & 0.69 & 2534 \\
\hline & External vol & $0.21 * * *$ & 0.47 & -0.24 & 0.00 & 0.19 & 0.41 & 0.69 & 1428 \\
\hline & External vol same f'n & 0.31 & 0.45 & -0.04 & 0.09 & 0.26 & 0.47 & 0.77 & 615 \\
\hline & External invol & $0.04 * * *$ & 0.49 & -0.41 & -0.14 & 0.06 & 0.29 & 0.53 & 479 \\
\hline & External invol same f'n & $0.08 * * *$ & 0.40 & -0.34 & -0.09 & 0.08 & 0.31 & 0.51 & 204 \\
\hline \multirow[t]{3}{*}{ Change in function } & Internal & 0.30 & 0.46 & 0 & 0 & 0 & 1 & 1 & 3641 \\
\hline & External vol & $0.57 * * *$ & 0.50 & 0 & 0 & 1 & 1 & 1 & 1428 \\
\hline & External invol & $0.57 * * *$ & 0.49 & 0 & 0 & 1 & 1 & 1 & 479 \\
\hline
\end{tabular}

Tests for difference versus all internal moves: $\uparrow \mathrm{p}<.1 ;{ }^{*} \mathrm{p}<.05 ;{ }^{* *} \mathrm{p}<.01 ; * * * \mathrm{p}<.001$ 
TABLE 2: MULTIVARIATE COMPARISON OF EFFECTS OF INTERNAL AND EXTERNAL MOBILITY

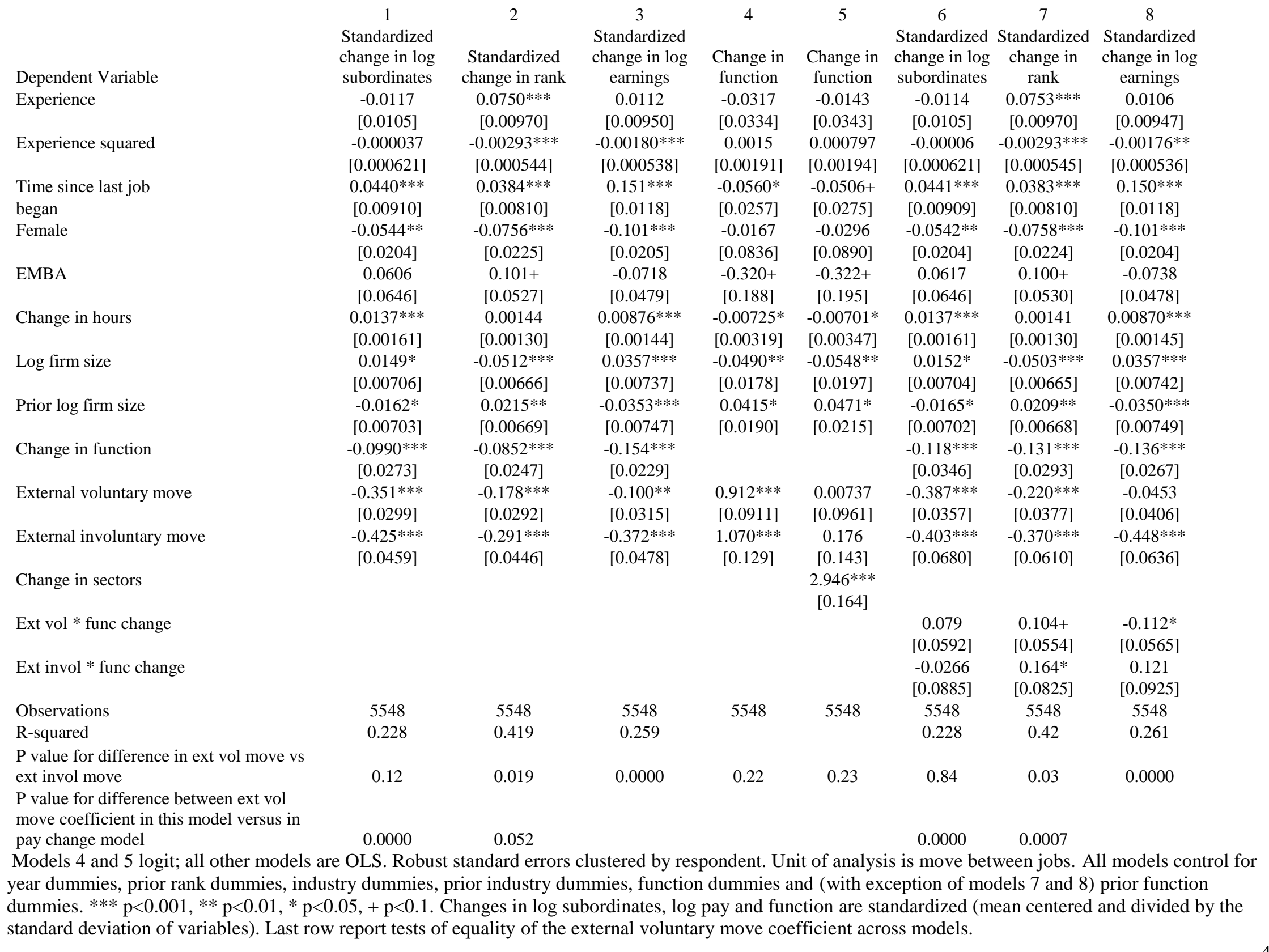


TABLE 3: DETERMINANTS OF PAY AND CAREER SATISFACTION IN 2010

Experience

Experience squared

Start date of current job

EMBA

Female

Log firm size

Unemp spells to date

Family break spells to date

Invol turnover to date

Internal moves to date

External vol moves to date

Function changes to date

Sector changes to date

Observations

R-squared

\section{0.}

1

Log earnings

2

34

Career Satisfaction

\begin{tabular}{l|ll}
$0.0329 *$ & 0.139 & 0.144
\end{tabular}

$\left[\begin{array}{lllll}0.0158] & {[0.0162]} & {[0.173]} & {[0.175]}\end{array}\right.$

$\begin{array}{lllll}-0.00034 & -0.0008 & -0.00249 & -0.00265\end{array}$

$\left[\begin{array}{lllll}{[0.000595]} & {[0.000609]} & {[0.00650]} & {[0.00657]}\end{array}\right.$

$-3.59 \mathrm{e}-05 * * \quad-3.19 \mathrm{e}-05 * \quad-1.87 \mathrm{E}-05 \quad-1.91 \mathrm{E}-05$

$[1.31 \mathrm{e}-05] \quad[1.34 \mathrm{e}-05] \quad[0.000142] \quad[0.000143]$

$\begin{array}{llll}0.150 * * * & 0.142 * * & 0.642 & 0.648\end{array}$

$\left[\begin{array}{ll|ll}{[0.0444]} & {[0.0453]} & {[0.489]} & \text { [0.492] }\end{array}\right.$

$-0.151 * * * \quad-0.157 * * *$

$-0.514+\quad-0.604 *$

$\left[\begin{array}{lllll}0.0253 & {[0.0258]} & {[0.279]} & {[0.281]}\end{array}\right.$

\begin{tabular}{ll|ll}
0.00298 & 0.00288 & $-0.174 * * *$ & $-0.168 * * *$
\end{tabular}

$\left[\begin{array}{lllll}0.00388 & {[0.00395]} & {[0.0426]} & {[0.0428}\end{array}\right.$

$\begin{array}{lllll}-0.0514 & -0.0664 & -0.737 & -0.852+\end{array}$

$\left[\begin{array}{lllll}0.0405] & {[0.0462]} & {[0.451]} & \text { [0.506] }\end{array}\right.$

$\begin{array}{llll}-0.264 * * * & -0.269 * * * & -1.071 & -1.005\end{array}$

$\left[\begin{array}{lllll}0.0743] & {[0.0764]} & {[0.825]} & {[0.836]}\end{array}\right.$

$\begin{array}{lllll}-0.115 * * * & -0.124 * * * & -1.318 * * * & -1.432 * * *\end{array}$

$\left[\begin{array}{lllll}{[0.0172]} & {[0.0179]} & {[0.191]} & {[0.196]}\end{array}\right.$

$0.0269 * * \quad 0.0407 * * *$

[0.00838] [0.00948]

$0.274 * *$

$0.387 * * *$

[0.0929] [0.104]

$\begin{array}{llll}-0.0022 & 0.00409 & -0.12 & -0.143\end{array}$

[0.0119]

[0.0133]

$-0.0325^{* *}$

[0.0109]

0.0182

[0.0206]

984

935

0.359

[0.132]

[0.145]

$-0.356 * *$

[0.119]

$0.746 * *$

[0.226]

$1004 \quad 951$

0.171

0.189

All models control for initial job function and initial industry. ${ }^{* * *} \mathrm{p}<0.001,{ }^{*} \mathrm{p}<0.01,{ }^{*} \mathrm{p}<0.05,+\mathrm{p}<0.1$. 
TABLE 4: MULTINOMIAL LOGIT FOR PROBABILITY OF DIFFERENT FORMS OF MOBILITY (VS INTERNAL MOVES)

\begin{tabular}{|c|c|c|c|c|c|c|}
\hline & \multicolumn{3}{|c|}{1} & \multicolumn{3}{|c|}{2} \\
\hline & No move & Ext voluntary & Ext invol & No move & Ext voluntary & Ext invol \\
\hline \multirow[t]{2}{*}{ Experience } & $0.102 * * *$ & $0.106 * * *$ & $0.0881 * *$ & $0.0874 * * *$ & $0.0660^{*}$ & 0.0391 \\
\hline & {$[0.0150]$} & {$[0.0241]$} & {$[0.0282]$} & {$[0.0224]$} & {$[0.0323]$} & {$[0.0367]$} \\
\hline \multirow[t]{2}{*}{ Experience squared } & -0.000264 & $-0.00652 * * *$ & -0.000142 & 0.00131 & $-0.00516 * *$ & 0.00131 \\
\hline & [0.000984] & {$[0.00170]$} & {$[0.00178]$} & [0.00110] & [0.00179] & [0.00189] \\
\hline \multirow{2}{*}{ Time in job } & $-0.993 * * *$ & $-0.496 * * *$ & $-0.370 * * *$ & $-1.046 * * *$ & $-0.490 * * *$ & $-0.331 * *$ \\
\hline & {$[0.0654]$} & {$[0.0785]$} & {$[0.113]$} & {$[0.0662]$} & {$[0.0809]$} & {$[0.114]$} \\
\hline \multirow[t]{2}{*}{ Time in job squared } & $0.0914 * * *$ & $0.0513 * * *$ & 0.0194 & $0.0916 * * *$ & $0.0488 * * *$ & 0.0162 \\
\hline & {$[0.00862]$} & {$[0.0106]$} & {$[0.0158]$} & {$[0.00835]$} & {$[0.0104]$} & [0.0156] \\
\hline \multirow{2}{*}{ Female } & $-0.0768+$ & 0.0352 & -0.0591 & 0.00697 & 0.0638 & -0.0177 \\
\hline & {$[0.0455]$} & {$[0.0684]$} & [0.0944] & [0.0469] & {$[0.0706]$} & [0.0965] \\
\hline \multirow[t]{2}{*}{ EMBA } & $0.338^{* *}$ & -0.0179 & $0.382 *$ & 0.0887 & -0.0242 & $0.441 *$ \\
\hline & {$[0.116]$} & {$[0.152]$} & {$[0.175]$} & {$[0.123]$} & {$[0.161]$} & {$[0.182]$} \\
\hline \multirow[t]{2}{*}{ Log firm size } & $-0.0556^{* * *}$ & $-0.0805^{* * *}$ & $-0.210 * * *$ & $-0.0487 * * *$ & $-0.0735^{* * * *}$ & $-0.193 * * *$ \\
\hline & {$[0.00850]$} & {$[0.0116]$} & {$[0.0132]$} & {$[0.00910]$} & {$[0.0126]$} & [0.0145] \\
\hline \multirow[t]{2}{*}{ Log earnings } & & & & 0.0104 & $-0.281 * * *$ & $-0.233^{* *}$ \\
\hline & & & & {$[0.0480]$} & {$[0.0733]$} & {$[0.0852]$} \\
\hline \multirow{2}{*}{ Number of prior jobs } & & & & $-0.126 * * *$ & -0.000136 & 0.0382 \\
\hline & & & & {$[0.0248]$} & {$[0.0313]$} & {$[0.0341]$} \\
\hline \multirow[t]{2}{*}{ Rank } & & & & $0.165 * * *$ & $0.109 * * *$ & $0.110 * * *$ \\
\hline & & & & [0.0169] & {$[0.0233]$} & [0.0289] \\
\hline \multirow[t]{2}{*}{ Log subordinates } & & & & $0.0910 * * *$ & $0.128 * * *$ & 0.039 \\
\hline & & & & [0.0189] & {$[0.0275]$} & [0.0345] \\
\hline Sector dummies & Yes & Yes & Yes & Yes & Yes & Yes \\
\hline Year dummies & Yes & Yes & Yes & Yes & Yes & Yes \\
\hline Function dummies & & & & Yes & Yes & Yes \\
\hline Observations & 22270 & 22270 & 22270 & 22270 & 22270 & 22270 \\
\hline
\end{tabular}

Each observation is a year spent by a respondent. Dependent variable is form of mobility during that year: No move, internal move, external voluntary move, external involuntary move. Excluded category is internal moves. 
FIGURE 1: SUMMARY OF THEORETICAL MODEL

\begin{tabular}{|c|c|c|}
\hline & $\begin{array}{l}\text { Source of Employers' Willingness } \\
\text { to Offer Job }\end{array}$ & $\begin{array}{l}\text { Source of Workers' Willingness to Enter } \\
\text { Job }\end{array}$ \\
\hline Internal Moves & $\begin{array}{l}\text { Observation of workers' prior } \\
\text { performance }\end{array}$ & $\begin{array}{rc}\longrightarrow & \text { Increased responsibilities } \\
\text { LEADING TO } \\
\text { - Increased pay } \\
\text { - In similar type of work }\end{array}$ \\
\hline External Moves & $\begin{array}{l}\text { Worker has prior experience at a } \\
\text { similar level }\end{array}$ & $\begin{array}{l}\text { - } \begin{array}{c}\text { No increase in responsibilities } \\
\text { BUT } \\
\text { OR } \\
\text { - Increased pay relative to prior job } \\
\text { Opportunity to engage in different } \\
\text { kinds of work }\end{array} \\
\text { OR } \\
\text { Forced to move by loss of prior job }\end{array}$ \\
\hline
\end{tabular}


APPENDIX 1: LIST OF FUNCTIONS AND INDUSTRIES BY FREQUENCY IN DATA

\begin{tabular}{|c|c|c|c|}
\hline Function & Frequency & Industry & Frequency \\
\hline Accounting & 29 & General Finance & 196 \\
\hline Advertising & 20 & Commercial Banking & 147 \\
\hline Business Development & 426 & Investment Banking & 617 \\
\hline Consulting & 794 & Brokerage & 47 \\
\hline Corporate Finance & 513 & Hedge Fund & 84 \\
\hline Engineering & 17 & Mutual Fund & 60 \\
\hline Finance & 152 & Investment management - other & 180 \\
\hline Financial Advisor & 29 & Private Equity & 217 \\
\hline Investment Banking & 401 & Venture Capital & 69 \\
\hline Investment Management & 255 & Insurance & 67 \\
\hline Private Equity/Venture Capital & 331 & Real Estate & 130 \\
\hline Financial Research & 94 & Other Financial Services & 154 \\
\hline Risk Management & 29 & General Business and Professional Services & 60 \\
\hline Trading & 83 & Accounting & 15 \\
\hline General Management & 653 & Advertising & 27 \\
\hline Healthcare/Healthcare Provision & 41 & Consulting, Management & 647 \\
\hline Human Resource Management & 47 & Consulting, Other & 107 \\
\hline Legal & 15 & General Health, Biomedical, and Pharma & 44 \\
\hline Information Technology & 77 & Biotech & 72 \\
\hline Operations & 204 & HealthCare Products & 60 \\
\hline Product Development & 176 & HMO/PPO/Health Services & 62 \\
\hline Marketing & 667 & Hospital & 34 \\
\hline Purchasing & 20 & Medical Equipment & 61 \\
\hline Real Estate & 118 & Pharmaceuticals & 165 \\
\hline Research & 25 & $\begin{array}{l}\text { General Manufacturing, Energy, and } \\
\text { Construction }\end{array}$ & 253 \\
\hline Sales & 151 & Automotive & 48 \\
\hline \multirow[t]{23}{*}{ Other } & 181 & Chemicals & 53 \\
\hline & & Energy & 149 \\
\hline & & General Technology, Media and Telecoms & 71 \\
\hline & & Computers & 61 \\
\hline & & Electronics, other & 70 \\
\hline & & Software & 277 \\
\hline & & Internet Products and services & 235 \\
\hline & & Telecoms & 132 \\
\hline & & Other Media & 129 \\
\hline & & Other Technology & 19 \\
\hline & & Consumer Products & 138 \\
\hline & & Food \& Beverage & 127 \\
\hline & & Government, National & 18 \\
\hline & & Government, State/Local & 18 \\
\hline & & Armed Forces & 13 \\
\hline & & International Development & 18 \\
\hline & & Education & 66 \\
\hline & & Other non profit & 39 \\
\hline & & Retail Sales & 120 \\
\hline & & Wholesale & 29 \\
\hline & & Transportation/Shipping & 39 \\
\hline & & Travel & 32 \\
\hline & & Other & 72 \\
\hline
\end{tabular}

